\title{
Knowledge, Attitude, and Practices of Pediatricians toward Oral Health of Asthma Patients
}

\author{
${ }^{1}$ Roopa P Shahapur, ${ }^{2}$ Praveen R Shahapur
}

\begin{abstract}
Background: Asthma is a multifactorial disease affecting the airways. Though it is a benign disorder, the treatment with medications such as bronchodilators, corticosteroids, and anticholinergic drugs may cause adverse effects on oral health.

Materials and methods: A questionnaire consisting of 16 closed-ended questions were mailed to pediatricians of Bijapur and Belgaum district. Of a total of 316, 96 duly filled questionnaires were collected.
\end{abstract}

Results: About 30 to $50 \%$ of the doctors were aware of the ill effects of medication and disease on the oral cavity. About $30 \%$ of the doctors advised preventive measures to their patients.

Conclusion: A multidisciplinary approach for treatment of the affected children is the key to improved health care delivery and better quality of life among these patients.

Keywords: Asthma, Oral heath, Pediatrician.

How to cite this article: Shahapur RP, Shahapur PR. Knowledge, Attitude, and Practices of Pediatricians toward Oral Health of Asthma Patients. World J Dent 2016;7(2):92-94.

Source of support: Nil

Conflict of interest: None

\section{INTRODUCTION}

Asthma is a multifactorial disease affecting millions of people worldwide. ${ }^{1}$ Though it is viewed as a fairly benign disorder, children with chronic medical disorders requiring long-term medications are at a risk of developing oral diseases. ${ }^{2}$ Several studies have been done to investigate the effect of asthma on oral health. Inspite of the confounding results, majority of the studies conclude that children with asthma have higher caries prevalence than their nonasthmatic counterparts. ${ }^{3-8}$ Asthmatics are at a risk of developing periodontal disease, oral ulcers, oral candidiasis, dental erosion, and halitosis.

With increasing number of asthma-affected patients, health care workers need to be adept at recognizing the

\footnotetext{
${ }^{1}$ Associate Professor, ${ }^{2}$ Professor and Head

${ }^{1}$ Department of Dentistry, BLDEU's SBM Patil Medical College Vijayapur, Karnataka, India

${ }^{2}$ Department of Microbiology, BLDEU's SBM Patil Medical College Vijayapur, Karnataka, India
}

Corresponding Author: Roopa P Shahapur, Associate Professor, Department of Dentistry, BLDEU's SBM Patil Medical College, Vijayapur, Karnataka, India, Phone: +918352260938 e-mail: shahapurroopa@gmail.com signs and symptoms of asthma-associated oral health problems. This study is aimed at assessing the knowledge, attitude, and practices of the pediatricians toward oral health of asthma patients.

\section{AIMS AND OBJECTIVES}

- To assess the awareness of pediatricians toward oral health among asthma patients.

- To know the precautions taken by pediatricians to prevent oral health hazards among asthma patients.

\section{MATERIALS AND METHODS}

This cross-sectional survey was performed using a closed-ended questionnaire. The questionnaire consisted of 16 questions that addressed various issues related to asthma and oral health, namely, effect of drugs on gingiva, teeth, mucosa, etc. The questionnaires were distributed among pediatricians of Bijapur and Belgaum district. Totally 316 questionnaires were distributed. Pediatricians were sent a letter explaining the aims and objectives of the study, as well as questionnaire and a selfaddressed envelope. A week after the questionnaire was mailed a reminder call was made to all the participants and enquired regarding the receipt of the questionnaire. Participants were requested to return the questionnaire at the earliest. Reminder calls were made twice at an interval of 1 week to mail the duly filled questionnaire in the self-addressed envelope to the investigator. The questionnaires thus collected were analyzed and subjected to statistical analysis.

\section{RESULTS}

Out of 316 questionnaires, 112 were distributed in Bijapur district and the rest $(n=204)$ in Belgaum district. As many as 28 and 68 duly filled questionnaires were collected from Bijapur and Belgaum respectively. Nonresponse rate of 25 and $33.3 \%$ was seen in Bijapur and Belgaum respectively.

Among the participating doctors, $31 \%$ treated asthma patients everyday and $50 \%$ treated once a week and the rest once a month.

About $38 \%$ of the doctors believed that an asthmatic child suffered from dental caries more often than a normal child, while $31 \%$ believed otherwise. As much 
Knowledge, Attitude, and Practices of Pediatricians toward Oral Health of Asthma Patients

Table 1: Response of pediatricians toward the questionnaire

\begin{tabular}{llll}
\hline & Yes & No & Do not know \\
\hline $\begin{array}{l}\text { Asthma child suffers more } \\
\text { commonly from dental caries }\end{array}$ & $38 \%$ & $31 \%$ & $31 \%$ \\
$\begin{array}{l}\text { Gingivitis is more common in } \\
\text { asthmatics }\end{array}$ & $12.5 \%$ & $50 \%$ & $37.5 \%$ \\
$\begin{array}{l}\text { Spacer used during inhalation } \\
\text { reduces ill effects of the drug on } \\
\text { oral cavity }\end{array}$ & $63 \%$ & $18.5 \%$ & $18.5 \%$ \\
$\begin{array}{l}\text { Asthmatic child suffers more } \\
\text { commonly from orofacial } \\
\text { abnormalities than the normal child }\end{array}$ & $38 \%$ & $30 \%$ & $32 \%$ \\
$\begin{array}{l}\text { Medications used to treat asthma } \\
\text { may cause candidiasis }\end{array}$ & $44 \%$ & $31 \%$ & $25 \%$ \\
$\begin{array}{l}\text { Calculus deposits are higher } \\
\text { among asthmatics than normal } \\
\text { children }\end{array}$ & $38 \%$ & $12 \%$ & $50 \%$ \\
\hline
\end{tabular}

as 31\% remained unaware of it. Among doctors who felt caries is more common in asthmatics, $18 \%$ believed it was because of change in oral flora, reduced oral $\mathrm{pH}$, and $56 \%$ remained unaware of it (Table 1).

About $68.5 \%$ of doctors prescribed inhaler as medication, $6 \%$ prescribed tablets, and $25 \%$ prescribed both of these including sugar-based syrups.

Half the pediatricians (50\%) did not agree that gingivitis is more common in asthmatic child, while $12.5 \%$ agreed with it and $37.5 \%$ remained unaware of it. Of the doctors who believed it was more common in an asthmatic child, half the doctors believed it was because of mouth breathing and altered immune response and the rest remained unaware of the cause.

A total of $63 \%$ of the doctors were of the opinion that spacer reduces the ill effects of medication on oral cavity, while $18.5 \%$ did not agree with it and $18.5 \%$ of them remained unaware of it; $90 \%$ of the doctors recommended spacer for their patients while using a spray; $38 \%$ of the doctors believed that asthmatic child suffers orofacial abnormalities more commonly than normal child and 30\% disagree with it, while 32\% were unaware of it; $44 \%$ of doctors believed that medications used to treat asthma may cause oral candidiasis, 31\% did not agree, while the rest were unaware of this; $38 \%$ of the doctors believed that calculus deposits are higher in asthmatic children, while $12 \%$ believed otherwise. The rest $(50 \%)$ were unaware of it; $41 \%$ of the doctors feel it is necessary to instruct the patients to rinse with water after medication, while the rest do not believe it. About $63 \%$ of doctors always recommend rinsing with water after medication and $38 \%$ recommend sometimes; $13 \%$ of doctors advice use of fluoride always, $69 \%$ advice sometimes, and $43.7 \%$ never advice. As much as $25 \%$ of doctors recommend their patients to visit dentist at regular intervals, $31 \%$ advised sometimes, while $44 \%$ never recommend dentist visit.

\section{DISCUSSION}

The present study was conducted to assess the knowledge, attitude, and practices of pediatricians toward oral health status of asthmatic children.

Several studies have suggested that people with asthma have a greater rate of caries development than do their nonasthmatic counterparts. ${ }^{4-12}$ The effect of reduced salivary flow has been elucidated in both human and animal studies. ${ }^{4,6,8,9}$ As reduced salivary flow is accompanied by concomitant increases in Lactobacilli and Streptococcus mutans ${ }^{13}$ in the oral cavity, it may contribute to increase in dental caries.

It was observed that while 30 to $50 \%$ of the doctors are aware of the ill effects of disease/medications, some of them are not adequately informed. The ill effects are due to side effect of drugs as well as the altered immune response. Hence, this calls for multidisciplinary approach for treatment of affected children.

It is strongly believed that drugs are a potential factor for caries development. Reduced salivary flow in return causes an increased count of Lactobacilli, S. mutans, ${ }^{13}$ whose role in caries initiation and progression is well documented. This effect is further augmented by medications containing fermentable carbohydrates and sugars.

Only 10 to $20 \%$ of the drug reaches the lungs, while the rest remains in the oropharynx. This remaining drug may result in throat irritation, dysphonia, and oropharyngeal candidiasis. This ill effect can be reduced by using a spacer and rinsing mouth with water after medication.

Inhaled corticosteroids are implied in causing gingivitis. Result of increased phosphorus and calcium in submaxillary and parotid saliva may also cause increase in gingivitis.

Dentofacial abnormalities in asthmatics have been assessed, evaluated, and discussed. This has been attributed to impaired nasorespiratory function and increased frequency of mouth breathing in asthmatics. Commonly found abnormalities are increased upper anterior and total anterior facial height, higher palatal vaults, greater overjets, and prevalence of posterior crossbite.

In a study conducted among pediatricians of Bangalore to assess their perceptions toward dental caries and sugar syrups, it was observed that $34.7 \%$ of them said that sugar-based syrups cause dental caries. In our study too, similar results were seen. ${ }^{14}$

\section{CONCLUSION}

- About half of the pediatricians participating in the study were well aware of the consequences of asthma on oral health. 
- Among these, about half of them practiced preventive measure and advised their patients a dental visit or oral hygiene instructions.

- Many of the doctors were not well informed about the ill effects of the asthma on oromaxillary complex, such as orofacial abnormalities, increased calculus deposits, and gingivitis.

- A multidisciplinary approach for treatment of the affected children is the key to improved health care delivery and better quality of life among these patients.

\section{REFERENCES}

1. Von Muteus E. The burden of childhood Asthma. Arch Dis Child 2000;82:112-115.

2. Schulman JD, Nunn ME, Taylor SE, Hidalgo FR. The prevalence of periodontal related changes in adolescents with Asthma: results of third annual national health and nutrition examination survey. Pediatr Dentist 2003 May-Jun; 25:279-284.

3. Thomas MS, Parolia A, Kundabala M, Vikram M. Asthma and oral health: a review. Aust Dent J 2010;55:128-133.

4. Shashikiran ND, Reddy VV, Raju PK. Effect of antiasthmatic medication on dental disease: dental caries and periodontal disease. J Indian Soc Pedod Prev Dent 2007 Apr-Jun;25(2): 65-68.
5. Reddy DK, Hegde AM, Munshi AK. Dental caries status of children with bronchial asthma. J Clin Pediatr Dent 2003;27:293-295.

6. Alavaikko S, Jaakkola MS, Tjäderhane L, Jaakkola JJ. Asthma and caries: a systematic review and meta-analysis. Am J Epidemiol 2011 Sep 15;174:631-641.

7. Hobson P. Sugar based medicines and dental disease. Community Dent Health 1985 Mar;2:57-62.

8. Dugmore CR, Rock WP. Asthma and tooth erosion: is there an association? Int J Paediatr Dent 2003 Nov;13(6):417-424.

9. Ersin NK, Gulen F, Eronat N, Cogulu D, Demir E, Tanaç R, Aydemir S. Oral and dental manifestations of young asthmatics related to medication, severity and duration of condition. Pediatr Int 2006 Dec;48(6):549-554.

10. Stensson M, Wendt LK, Koch G, Oldaeus G, Birkhed D. Oral health in preschool children with asthma. Int J Paediatr Dent 2008 Jul;18(4):243-250.

11. McDerra EJ, Pollard MA, Curzon ME. The dental status of asthmatic British school children. Pediatr Dent 1998 JulAug;20(4):281-287.

12. Milano M, Lee JY, Donovan K, Chen JW. A cross-sectional study of medication-related factors and caries experience in asthmatic children. Pediatr Dent 2006 Sep-Oct;28(5):415-419.

13. Almstahl A, Wikstrom M. Oral microflora in subjects with reduced salivary secretion. J Dent Res 1999 Aug;78(8):1410-1416.

14. Murthy GA, Mohandas U. The knowledge, attitude and practice in prevention of dental caries amongst pediatricians in Bengaluru: a cross-sectional study. J Indian Soc Pedod Prev Dent 2010 Apr-Jun;28(2):100-103. 